\title{
Faktor yang Berhubungan dengan Pemberian ASI Eksklusif pada Ibu Bekerja di Kabupaten Ogan Komering Ulu
}

\author{
Nency Agustia ${ }^{1}$, Rizanda Machmud ${ }^{2}$, Elly Usman ${ }^{3}$
}

\begin{abstract}
Abstrak
Ogan Komering Ulu (OKU) memiliki angkatan kerja sebanyak 65.917 dari 97.628 Wanita Usia Subur. Di Kabupaten Ogan Komering Ulu cakupan ASI eksklusif masih belum memenuhi target yaitu 48,5\% dari 80\%. Kebijakan mengenai ASI eksklusif di tempat kerja telah ada, namun masih banyak tempat kerja yang belum melaksanakan kebijakan tersebut.Tujuan: Menganalisis faktor yang berhubungan dengan pemberian ASI eksklusif pada ibu bekerja di Kabupaten OKU. Metode: Studi mixed method desain sequential explanatory. Sampel kuantitatif diambil menggunakan multistage sampling pada Sembilan puluh dua ibu bekerja menyusui yang memiliki anak usia 0-2 tahun di OKU antara November 2018-Maret 2019. Responden penelitian kualitatif dengan indept interview kepada pengelola program gizi dinas kesehatan, kabid hubungan indsutrial dinas tenaga kerja dan transmigrasi, kasie pemberdayaan perempuan dan perlindungan anak, pemegang program gizi puskesmas sukaraya dan puskesmas tanjung agung, pimpinan tempat kerja dan responden Focus Group Discussion (FGD) yaitu ibu-ibu bekerja yang menyusui. Hasil: Kuantitatif didapatkan pengetahuan $(p=0,245)$, Sikap $(p=0,423)$, fasilitas laktasi $(p=0,233)$, dukungan suami $(p=$ $0,958)$, dukungan atasan kerja $(p=0,641)$. Hasil penelitian kualitatif menjelaskan bahwa kebijakan ASI Ekslusif di tempat kerja masih banyak ditemukan kendala berupa kurangnya sosialisasi, belum ada alokasi dana, tenaga dan sarana khusus untuk pelaksanaan. Simpulan: Pelaksanaan kebijakan ASI Eksklusif pada ibu bekerja di OKU belum terlaksana dengan baik karena belum adanya Perda Khusus tentang ASI Eksklusif di tempat kerja.
\end{abstract}

Kata kunci: ASI eksklusif lbu bekerja, pengetahuan, mixed method

\section{Abstract}

Ogan Komering Ulu has the workforce of 65,917 out of 97,628 fertile women. The coverage of exclusive breastfeeding in OKU is $48.5 \%$ from targeted $80 \%$. A policy regarding exclusive breastfeeding in the workplace, but there are still many workplaces that have not implemented the policy. Objectives: To analyzed the factors associated with exclusive breastfeeding among working mothers in OKU. Methods: The study used mixed method sequential explanatory design. Quantitative samples were taken by using multistage sampling in ninety two breastfeeding working mothers who had children aged less than equal to two years old between November 2018-March 2019. Qualitative research was achieved by indept interview to the nutrition program manager of the health office, head of industrial relations in manpower and transmigration office, head of women's empowerment and child protection, nutrition program manager of sukaraya and tanjung agung health center, workplace Leaders, and Focus Group Discussion $(F G D)$ which were breastfeeding working mothers. Results: The quantitative analysis showed that knowledge ( $p=$ $0.245)$, attitude $(p=0.423)$, lactation facilities $(p=0.233)$, husband support $(p=0.958)$, work supervisor support $(p=$ 0.641). The results of the qualitative study explained that many obstacles were found for implementing exclusive breastfeeding policy in the workplace, including lack of socialization, funds, staff and facilities for implementation. Conclusions: The implementation of the exclusive breastfeeding policy had not been implemented properly due to not avaible the regional regulation on exclusive breastfeeding in the workplace.

Keywords: exclusive breastfeeding among working mothers, knowledge, mixed method 
Affiliasi penulis: 1. Prodi Magister Kebidanan Fakultas Kedokteran Universitas Andalas Padang (FK Unand), 2.Bagian IImu Kesehatan Masyarakat FK Unand 3. Bagian Farmakologi FK Unand

Korespondensi: Rizanda Machmud, Email: nencyagsutia96 @gmail.Telp: 081271400401

\section{PENDAHULUAN}

World Health Organization (WHO) dan United Nations International Children's (UNICEF) dalam Global Strategy for Infant and Young Child Feeding mengatur pola pemberian makan terbaik pada bayi dari lahir sampai usia dua tahun untuk meningkatkan kualitas kesehatan pada bayi dan anak dengan cara memberikan air susu ibu (ASI) kepada bayi segera dalam waktu satu jam setelah bayi lahir, memberikan ASI saja atau pemberian ASI secara eksklusif sejak lahir sampai bayi berusia 6 (enam) bulan, memberikan makanan pendamping air susu ibu (MPASI) sejak bayi berusia 6 (enam) bulan sampai 24 bulan serta meneruskan pemberian ASI sampai anak berusia 24 bulan atau lebih. ${ }^{1}$

Berdasarkan Hasil Pemantauan Status Gizi di Indonesia tahun 2017 diketahui cakupan ASI eksklusif sebanyak 35,7\%. Provinsi Sumatera Selatan merupakan provinsi urutan kedua setelah DIY $(61,4 \%)$ yang target ASI eksklusif tertinggi yaitu sebanyak $48,1 \%$, Cakupan tersebut masih jauh dari target nasional sebanyak $80 \% .^{2}$ Salah satu penyebab tidak ASI eksklusif adalah pekerjaan. Ibu yang bekerja di luar rumah memiliki keterbatasan waktu untuk menyusui bayinya, tidak memiliki tempat penitipan anak, fasilitas tempat penyimpanan ASI di tempat kerja, dan kebijakan-kebijakan kelonggaran waktu di tempat kerja.

Kabupaten Ogan Komering Ulu (OKU) memiliki angkatan kerja wanita yang bekerja sebanyak 65.917 dari 97.628 Wanita Usia Subur, dimana wanita tersebut berada di usia reproduktif (15-49 tahun). ${ }^{4}$ Berdasarkan survei pendahuluan yang dilakukan pada 30 ibu bekerja hanya 13 ibu yang memberikan ASI eksklusif pada bayi. Dari 13 ibu tersebut 5 ibu tidak mengetahui pengertian ASI eksklusif, 6 ibu sangat setuju memberikan ASI eksklusif dengan cara diperah, 4 ibu yang memiliki fasilitas laktasi di tempat kerja, namun tidak ada yang memenuhi standar dan 4 ibu yang mendapatkan dukungan emosional dari suami.
Padahal pemerintah telah mengeluarkan berbagai kebijakan untuk meningkatkan ASI eksklusif di Indonesia. Salah satu kebijakan tersebut adalah melalui Program ASI eksklusif. Tempat kerja harus mendukung program ASI eksklusif yang sesuai dengan ketentuan di tempat kerja. Tempat kerja terdiri atas: Perusahaan; dan Perkantoran milik pemerintah, pemerintah daerah, dan swasta. $^{5}$ Ada beberapa kebijakan tentang Peningkatan pemberian ASI eksklusif selama waktu kerja di tempat kerja, namun masih banyak tempat kerja yang belum mendukung program tersebut. Studi pendahuluan yang dilakukan kepada 30 ibu menyusui yang bekerja hanya terdapat 4 tempat kerja yang memiliki ruang untuk menyusui dan hanya 1 tempat yang memiliki fasilitas tempat penyimpanan ASI perah. Padahal salah satu kontrak tempat kerja terdapat hak pekerja dalam hal kesempatan melakukan laktasi dan kewajiban menyediakan fasilitas laktasi. Alasan tempat kerja beragam ada yang mengatakan belum mengetahui adanya kebijakan tersebut dan sulitnya sarana dan prasarana seperti penyediaan ruang untuk memerah ASI.

Penelitian ini bertujuan untuk mengetahui faktor yang berhubungan dengan Pemberian ASI eksklusif pada Ibu Bekerja di Kabupaten Ogan Komering Ulu Tahun 2019

\section{METODE}

Penelitian ini menggunakan mixed method dengan pendekatan sequential explanatory. Penelitian kuantitatif dengan desain cross sectional. Sampel sebanyak 92 ibu bekerja menyusui dengan teknik Multi stage sampling. Data dikumpulkan menggunakan kuesioner. Analisis dilakukan secara univariat dengan distribusi frekuensi, bivariat dengan chi-square dan analisis multivariat dengan analisis logistik berganda. Kriteria inklusi dalam penelitian ini adalah ibu bekerja menyusui yang memiliki anak 0-24 bulan, tidak memiliki kontraindikasi dalam menyusui, dan bersedia menandatangani informend consent.

Variabel dependen dalam penelitian ini adalah Pemberian ASI eksklusif dan variabel independent dalam penelitian ini adalah pengetahuan, sikap, fasilitas laktasi, dukungan suami dan dukungan atasan 
kerja. instrument dalam penelitian ini telah diuji validitas dan reliabilitasnya.

Data pengetahuan diperoleh dengan cara meminta responden untuk mengisi angket. Kategori pengetahuan dikatakan tinggi jika > 60 dan rendah jika $\leq 60$. Kategori sikap dikatakan positif jika $\geq 76 \%-100 \%$ dan dikatakan negatif jika $<76 \%$. Kategori fasilitas laktasi dikatakan ada dan tidak ada. Kategori dukungan suami dikatakan mendukung jika $>80 \%$ dan tidak mendukung jika $\leq 80 \%$. Kategori dukungan atasan kerja dikatakan mendukung jika $>80 \%$ dan tidak mendukung jika $\leq 80 \%$.

Metode kualitatif untuk mendukung data kuantitatif yang diperoleh pada tahap awal dengan pendekatan sistem. Pemilihan informan pada penelitian ini menggunakan teknik purposive sampling. Informan dalam penelitian ini adalah pengelola program gizi dinas kesehatan, kepala bidang (Kabid) hubungan industrial, Kabid pemberdayaan perempuan, pengelola program gizi Puskesmas Sukaraya, pengelola program gizi Puskesmas Tanjung Agung, Kasubbag PTP dinas pendidikan, dan Ketua Yayasan Sentosa Bhakti serta 4 orang Focus Group Discussion (FGD) yaitu ibu bekerja yang menyusui.

Pengumpulan data primer melalui angket, wawancara terstruktur, FGD dan observasi untuk mengumpulkan informasi mengenai pemberian ASI eksklusif. Data sekunder didapatkan melalui telaah dokumen yang berhubungan dengan Pemberian ASI eksklusif di tempat kerja seperti cakupan ASI eksklusif, jumlah tenaga terlatih, jumlah fasilitas laktasi di tempat kerja, sarana dan prasarana, peraturan internal di tempat kerja dan dokumen pendukung lainnya. Penelitian ini dilakukan setelah mendapatkan kelayakan etik (ethical cleareance) dari komite etika penelitian Fakultas Kedokteran Universitas Andalas Padang.
HASIL

Data penelitian yang diperoleh dengan menyebarkan angket pada 92 responden di Kabupaten OKU setelah data dianalisis secara univariat, bivariat dan multivariat kemudian diperoleh hasil sebagai berikut.

Tabel 1. Karakteristik responden pemberian ASI eksklusif pada ibu bekerja di Kabupaten Ogan Komering Ulu

\begin{tabular}{lcc}
\hline \multicolumn{1}{c}{$\begin{array}{c}\text { Karakteristik } \\
\text { Responden }\end{array}$} & f & $\%$ \\
\hline Usia & & \\
$20-35$ & 75 & 81,5 \\
$>35$ & 17 & 18,5 \\
Pendidikan & & \\
SMP & 1 & 1,1 \\
SMA & 6 & 6,5 \\
DIII/DIV/S1 & 83 & 90,2 \\
S2 & 2 & 2,2 \\
Paritas & & \\
1 & 44 & 47,8 \\
$2-3$ & 48 & 52,2 \\
\hline
\end{tabular}

Berdasarkan Tabel 1 tampak 75 (81,5\%) responden berusia 20-35 tahun pada masa menyusui di Kabupaten Ogan Komering Ulu.

Tabel 2. Pemberian ASI eksklusif pada ibu bekerja di Kabupaten Ogan Komering Ulu

\begin{tabular}{lcc}
\hline $\begin{array}{c}\text { Pemberian ASI } \\
\text { Eksklusif }\end{array}$ & f & $\%$ \\
\hline Ya & 58 & 63,0 \\
Tidak & 34 & 37,0 \\
Jumlah & 92 & 100 \\
\hline
\end{tabular}

Berdasarkan Tabel 2 tampak 34 (37\%) ibu tidak memberikan ASI eksklusif di Kabupaten Ogan Komering Ulu. 
Tabel 3. Distribusi frekuensi dan persentase faktor responden pemberian ASI eksklusif pada ibu bekerja di Kabupaten Ogan Komering Ulu

\begin{tabular}{|c|c|c|}
\hline Variabel & $f$ & $\%$ \\
\hline \multicolumn{3}{|l|}{ Pengetahuan } \\
\hline Rendah & 71 & 77,2 \\
\hline Tinggi & 21 & 22,8 \\
\hline \multicolumn{3}{|l|}{ Sikap } \\
\hline Negatif & 24 & 26,1 \\
\hline Positif & 68 & 73,9 \\
\hline \multicolumn{3}{|l|}{ Fasilitas laktasi } \\
\hline Tidak ada & 62 & 67,4 \\
\hline Ada & 30 & 32,6 \\
\hline \multicolumn{3}{|l|}{ Dukungan suami } \\
\hline Tidak mendukung & 66 & 71,7 \\
\hline Mendukung & 26 & 28,3 \\
\hline \multicolumn{3}{|c|}{ Dukungan atasan kerja } \\
\hline Tidak mendukung & 72 & 78,3 \\
\hline Mendukung & 20 & 21,7 \\
\hline
\end{tabular}

Berdasarkan tabel diatas diperoleh bahwa sebagian besar ibu memiliki pengetahuan rendah, sebagian besar ibu memiliki sikap positif, lebih dari separuh ibu memiliki fasilitas laktasi di tempat kerja, sebagian besar ibu tidak memiliki dukungan dari suami dan sebagian besar ibu bekerja menyusui tidak memiliki dukungan dari atasan kerja dalam pemberian ASI eksklusif.

Tabel 4. Faktor yang berhubungan dengan pemberian ASI Eksklusif pada ibu bekerja di Kabupaten Ogan Komering Ulu

\begin{tabular}{|c|c|c|c|c|c|c|c|}
\hline \multirow[t]{3}{*}{ Variabel } & \multicolumn{4}{|c|}{$\begin{array}{c}\text { Pemberian ASI } \\
\text { Eksklusif }\end{array}$} & \multirow{2}{*}{\multicolumn{2}{|c|}{ Total }} & \multirow[t]{3}{*}{$\mathbf{p}$} \\
\hline & \multicolumn{2}{|c|}{ Tidak } & \multicolumn{2}{|l|}{ Ya } & & & \\
\hline & $f$ & $\%$ & $\mathbf{f}$ & $\%$ & $\mathbf{f}$ & $\%$ & \\
\hline \multicolumn{8}{|c|}{ Pengetahuan } \\
\hline Rendah & 29 & 40,8 & 42 & 59,2 & 71 & 100 & \multirow[t]{2}{*}{0,245} \\
\hline Tinggi & 5 & 23,8 & 16 & 76,2 & 21 & 100 & \\
\hline \multicolumn{8}{|l|}{ Sikap } \\
\hline Negatif & 11 & 45,8 & 13 & 54,2 & 24 & 100 & \multirow[t]{2}{*}{0,423} \\
\hline Positif & 23 & 33,8 & 45 & 66,2 & 68 & 100 & \\
\hline \multicolumn{8}{|c|}{ Fasilitas laktasi } \\
\hline Tidak & 26 & 41,9 & 36 & 58,1 & 62 & 100 & \multirow[t]{3}{*}{0,233} \\
\hline Ada & & & & & & & \\
\hline Ada & 8 & 26,7 & 22 & 73,3 & 30 & 100 & \\
\hline \multicolumn{8}{|c|}{ Dukungan suami } \\
\hline Tidak & 25 & 37,9 & 41 & 62,1 & 66 & 100 & \multirow[t]{3}{*}{0,958} \\
\hline Mendukung & & & & & & & \\
\hline Mendukung & 9 & 34,6 & 17 & 65,4 & 26 & 100 & \\
\hline \multicolumn{8}{|c|}{ Dukungan atasan kerja } \\
\hline Tidak & 28 & 38,9 & 44 & 61,1 & 72 & 100 & \multirow[t]{3}{*}{0,641} \\
\hline Mendukung & & & & & & & \\
\hline Mendukung & 6 & 30,0 & 14 & 70,0 & 20 & 100 & \\
\hline
\end{tabular}

Berdasarkan Tabel 4 dapat dilihat bahwa tidak ada hubungan antara pengetahuan $(p=0,245)$, sikap $(p=0,423)$, fasilitas laktasi $(p=2,33)$, dukungan suami $(p=0,958)$ dan dukungan atasan kerja $(0,641)$ dengan pemberian ASI Eksklusif pada Ibu Bekerja di Kabupaten Ogan Komering Ulu, didapatkan pada semua variabel dengan $p>0,05$ yang berarti tidak ada hubungan.

Tabel 5. Model prediksi multivariat

\begin{tabular}{lrrrl}
\hline \multicolumn{1}{c}{ Kriteria } & Model & Model & Model & Model \\
& $\mathbf{0}$ & $\mathbf{1}$ & $\mathbf{2}$ & $\mathbf{3}$ \\
\hline Pengetahuan & 0,344 & 0,347 & 0,368 & 0,280 \\
Sikap & 0,503 & 0,506 & 0,501 & - \\
Fasilitas laktasi & 0,484 & 0,483 & 0,287 & 0,283 \\
Dukungan Suami & 0,907 & - & - & - \\
Dukungan Atasan & 0,772 & 0,782 & - & - \\
kerja & & & & \\
\hline
\end{tabular}

Berdasarkan Tabel 5 dapat dilihat bahwa variabel dukungan suami mempunyai $p$ tertinggi $(0,907)$ sehingga dikeluarkan pertama kali dari model. Permodelan tahap kedua dengan mengeluarkan variabel dukungan atasan kerja $(p=0,782)$. Tahap ketiga dengan mengeluarkan variabel Sikap $(p=0,501)$ dari model.

Tabel 6. Hasil akhir permodelan

\begin{tabular}{llllll}
\hline Variabel & B & Wald & Sig & OR & $\begin{array}{l}\mathbf{C l} \\
\mathbf{9 5 \%}\end{array}$ \\
\hline Pengetahuan & 0,793 & 1,959 & 0,162 & 2,210 & $0,728-$ \\
& & & & & 6,705 \\
\hline
\end{tabular}

Pemberian ASI ekslusif pada ibu bekerja di Kabupaten Ogan Komering Ulu sudah mulai berjalan. Sosialisasi ke pimpinan kerja sudah dilakukan dalam kegiatan yang diadakan oleh Kabid hubungan industrial Disnakertrans, namun secara khusus membahas kebijakan di tempat kerja belum ada karena terkendala dengan dana. Sosialisasi ke ibu bekerja belum dilakukan oleh Dinas PPPA. Penyebaran bahan bacaan mengenai ASI eksklusif secara umum telah dilakukan oleh dinas kesehatan melalui fasilitas pelayanan kesehatan saat ibu berkunjung. Pembagian tugas dan tanggungjawab dari 
masing-masing instansi belum ada untuk pemberian ASI eksklusif pada ibu bekerja. Tenaga terlatih masih kurang. OKU hanya memiliki 14 konselor ASI yang tersebar di Pelayanan kesehatan dan belum ada di tempat kerja. Dana khusus ASI eksklusif hanya bersifat umum belum tersedia secara khusus untuk di tempat kerja. masih banyak tempat kerja yang belum menyediakan anggaran untuk meningkatkan pemberian ASI eksklusif pada ibu bekerja di tempat kerja.

Perencanaan hanya sebatas ASI eksklusif secara umum, sehingga belum ada pembagian tugas khusus ASI eksklusif di tempat kerja. Dinas Kesehatan sedang berupaya membentuk kelompok pendukung ASI yang sebelumnya gagal dibentuk. Dinas PPPA telah mendata tempat kerja yang memiliki ruang ASI. Pelaksanaan ASI eksklusif di Kabupaten OKU sudah mulai dilaksanakan, namun belum optimal karena belum adanya kebijakan daerah yang membahas tentang ASI eksklusif di tempat kerja sehingga pengawasan untuk pemberian ASI eksklusif di tempat kerja belum ada yang menyebabkan pimpinan kerja belum berencana untuk membuat kebijakan di tempat kerja mereka masing-masing karena belum ada sanksi yang tegas jika tidak dilaksanakan.

Hasil FGD pada ibu-ibu bekerja yang menyusu yang bekerja di pemerintahan dan swasta didapatkan bahwa tempat kerja mereka ada yang memiliki ruang ASI dan ada juga yang tidak, untuk penyediaan fasilitas laktasi yang sesuai standar minimal belum ada, hanya sebatas memiliki ruang ASI. Dukungan atasan kerja berupa pemberian waktu untuk menyusui sudah ada dan disetiap tempat kerja berbeda-beda aturannya seperti diberikan waktu istirahat 1 jam, diizinkan pulang, jam kerja yang sama dengan yang tidak menyusui, istirahat sebentar ditambah tidak adanya fasilitas menyusui seperti lemari penyimpan ASI dan ruang ASI yang nyaman membuat ibu enggan untuk menyusui.

\section{PEMBAHASAN}

Hasil penelitian ini menunjukkan sebagian besar ibu memiliki pengetahuan yang rendah $(77,2 \%)$ mengenai ASI eksklusif diantaranya sebanyak (19,6\%) ibu mengetahui manfaat ASI eksklusif bagi ibu. Ibu-ibu tersebut beranggapan bahwa menyusui dapat membuat payudara menjadi kendur, sebanyak $(27,2 \%)$ ibu yang mengetahui cara menyimpan ASI perah dan sebanyak (37\%) ibu yang mengetahui wadah yang tepat untuk menyimpan ASI perah padahal dengan penyimpanan ASI perah yang benar akan membuat komposisi ASI terjamin untuk bayi, serta responden banyak menjawab menggunakan dot untuk memberikan ASI perah (17,4\%), seharusnya dot tidak dianjurkan karna dapat membuat bayi bingung puting.

Sikap positif responden dipengaruhi oleh pengalaman ibu mengenai pentingnya ASI 6 bulan pertama kehidupan. Responden sebagian besar bersikap tidak malu untuk menyusui di depan umum, pentingnya menyusui selama enam bulan dan setuju untuk memerah ASI saat bekerja merupakan faktor penting dalam membatasi prevalensi menyusui. Temuan dari penelitian ini terdapat $25 \%$ ibu yang setuju menggunakan susu formula dan ditemukan juga sebanyak $37 \%$ ibu bekerja yang tidak memberikan ASI eksklusif. Penelitian pada 30 provinsi di Iran secara didapatkan hasil bahwa menggunakan dot $(\mathrm{aOR}=2,6$, $95 \% \mathrm{Cl}, 1,38,4,19)$ dan susu formula atau botol lainnya (aOR $=12,95 \% \mathrm{Cl}, 5,02,20,84)$ meningkatkan risiko untuk berhenti menyusui dini. ${ }^{6}$

Pada penelitian ini didapatkan responden yang sangat setuju (21,8\%) bahwa menyusui menurunkan ikatan antara ibu dan bayi. Penggunaan susu formula juga dikaitkan dengan ketidaktahuan ibu mengenai manfaat $\mathrm{ASI}$ dan praktik rumah sakit yang tidak tepat. ${ }^{7}$ Di Iran; Pemerintah mengendalikan impor dan penjualan pengganti ASI. Formula hanya tersedia dengan resep dokter, dan kaleng harus membawa label generik; tidak ada nama merek, gambar atau pesan promosi yang diperbolehkan. Di Brasil; semua iklan dan promosi pengganti ASI untuk anak-anak hingga usia 2 tahun dilarang dan peringatan kesehatan utama diperlukan pada semua pengganti ASI, botol susu, dan dot. Di Papua Nugini; penjualan botol susu, cangkir, dot dan boneka benar-benar dikontrol, dan ada larangan iklan produk-produk ini serta pengganti $\mathrm{ASI}^{8}$

Fasilitas menyusui hanya berupa ruang menyusui di tempat ibu bekerja sebanyak (32,6\%), sehingga ibu terhambat dalam pemberian ASI eksklusif karena hanya beberapa tempat kerja yang 
memiliki ruang menyusui, sarana dan prasarana di ruang menyusui yang belum sesuai standar minimal dan sesuai kebutuhan untuk menyusui, terbatasnya waktu dimana responden harus membagi waktu istirahat untuk makan, sholat dan memompa ASI. Sehingga waktu yang singkat tersebut tidak cukup untuk dapat memompa ASI dengan rileks dan akhirnya tidak menghasilkan ASI perah yang cukup banyak. Penelitian lain juga mengatakan penyediaan fasilitas menyusui akan memberikan manfaat bagi atasan kerja untuk memberikan masa cuti hamil yang pendek pada ibu bekerja. ${ }^{9}$

Temuan ini mirip penelitian lain dimana lbu yang kembali bekerja setelah masa cuti selesai memiliki tantangan dalam melanjutkan menyusui. Kemungkinan hambatan terhadap pemberian ASI secara berkelanjutan pada ibu bekerja seperti kurangnya fasilitas menyusui dan kurangnya istirahat saat bekerja, sehingga sulit untuk melakukan pekerjaan dan kewajiban menyusui secara bersamaan. ${ }^{10}$ Penelitian di Malaysia sehubungan dengan fasilitas menyusui pada ibu yang bekerja di tempat kerja yang tidak menyediakan lemari es lebih mungkin untuk berhenti menyusui. ${ }^{11 .}$ ASI dapat disimpan pada suhu kamar ruang 4-8 jam, didinginkan sampai 8 hari, dan dibekukan selama beberapa bulan. $^{12}$ Sebagian besar wanita dapat memeras ASI atau menyusu dalam waktu kurang dari satu jam ketika tempat kerja mendukung pemberian ASI. Penelitian yang dilakukan di Iran didapatkan bahwa rekomendasi keluarga merupakan 20\% penyebab yang memengaruhi para ibu untuk menghentikan pemberian ASI Ekslusif. ${ }^{6}$ Keberhasilan menyusui eksklusif dan melanjutkan menyusui sampai 12 bulan secara signifikan lebih tinggi pada kelompok suami yang mempelajari manajemen laktasi dan mendukung serta membantu ibu dalam menyusui. ${ }^{12}$

Banyak alasan ibu bekerja berhenti menyusui saat kembali bekerja. Atasan kerja yang tidak mendukung ibu saat berpisah dengan anak pada masa menyusui akan berdampak dalam mempertahankan pemberian ASI saat bekerja. Sebuah penelitian di Nigeria pada ibu bekerja di Bank, hanya $10 \%$ responden melaporkan memiliki dukungan dari tempat kerja untuk pemberian ASI eksklusif. ${ }^{13}$ Tidak jauh berbeda pada penelitian ini, sebanyak
$21,7 \%$ ibu bekerja yang mendapatkan dukungan dari atasan. Alasan pertama ibu berhenti menyusui saat kembali bekerja adalah dukungan tempat kerja dan managerial (44\%). Ibu bekerja yang telah membicarakan dengan atasan kerja sebelum cuti hamil, pengurangan waktu kerja dan fleksibilitas waktu istirahat berkemungkinan akan terus menyusui setelah kembali bekerja. ${ }^{14}$ Penelitian di Malaysia sehubungan dengan kurangnya waktu pada ibu yang menyusui di tempat kerja lebih mungkin untuk berhenti menyusui. ${ }^{11}$ Dukungan atasan kerja yang rendah mengenai pemberian asi eksklusif mungkin disebabkan atasan kerja belum mendapatkan sosialisasi mengenai aturan pemberian ASI eksklusif di tempat kerja akan berpengaruh terhadap Pemberian ASI eksklusif pada ibu bekerja.

Pada penelitian ini tidak terdapat hubungan antara pengetahuan ibu, sikap ibu, fasilitas laktasi, dukungan suami dan dukungan atasan kerja dengan pemberian ASI eksklusif disebabkan kriteria insklusi yang berbeda, hasil ukur yang berbeda, proporsi sampel yang tidak tersebar rata. Adanya faktor lain yang berpengaruh kuat seperti gencarnya promosi susu formula yang mempengaruhi ibu tentang keunggulan ASI dibandingkan dengan susu formula, faktor orangtua yang dianggap lebih berpengalaman dalam menyelesaikan masalah menyusui dibandingkan suami, faktor rekan kerja yang tidak mengetahui manfaat ASI sehingga akan enggan membantu ibu untuk menukar jam kerja saat ibu ingin menyusui.

Kebijakan adalah aturan tertulis yang merupakan keputusan formal organisasi, yang bersifat mengikat, yang mengatur perilaku dengan tujuan untuk menciptakan tata nilai baru dalam masyarakat. Hasil penelitian mengenai proses sosialisasi yang dilakukan dinas kesehatan, dinas ketenagakerjaan, dinas pemberdayaan perempuan dan perlindungan anak ke perusahaan, perkantoran milik pemerintah, pemerintah daerah dan swasta telah dilakukan. Sosialisasi tersebut hanya bersifat mengimbau atasan kerja, tidak memiliki sanksi, belum pernah dilaksanakan penyuluhan secara langsung dalam bentuk pertemuan langsung khusus membahas pemberian ASI eksklusif di tempat kerja. Pihak puskesmas hanya melakukan sosialisasi ke ibu 
bekerja yang hamil yang datang ke wilayah kerja puskesmas. Penelitian ini sejalan dengan Paramashanti di Kabupaten Bantul tahun 2017, menunjukkan bahwa agar kebijakan dapat terlaksana diperlukan sosialisasi antar semua lintas sektor terkait program pemberian ASI eksklusif. ${ }^{15}$

Kebijakan yang sudah dikomunikasikan secara jelas dan konsisten, tetapi apabila implementor kekurangan sumber daya untuk melaksanakan, implementasi tidak akan berjalan efektif. Sumber daya adalah faktor penting untuk implementasi kebijakan agar efektif. Tenaga merupakan hak dan kebutuhan dasar manusia, dimana pemerintah mempunyai kewajiban untuk mengadakan dan mengatur upaya pelayanan kesehatan yang dapat dijangkau rakyatnya. Permasalahan pada tenaga ditemukan pada belum tersedianya tim khusus pelaksanaan dan pengawasan Program ASI eksklusif di tempat kerja hanya ada program ASI eksklusif. Tim pelaksana dan pengawasan berpengaruh terhadap sosialisasi ke pekerja/buruh, atasan kerja. Hal ini menjadi salah satu masalah dalam pelaksanaan proses pemberian ASI eksklusif di tempat kerja. Tenaga terlatih pemberian ASI eksklusif yang kurang juga berpengaruh pada dukungan terhadap ibu menyusui yang memiliki masalah dalam menyusui. Salah satu upaya yang mungkin dapat dilakukan Pemerintah Kabupaten OKU adalah menyiapkan dana untuk insentif untuk pelatihan menambah tenaga konselor ASI. Upaya lain adalah pembentukan Kelompok pendukung ASI di masyarakat, maka kuantitas dari konselor ASI akan bertambah dan capaian ASI eksklusif akan meningkat.

Dana merupakan suatu hal yang pasti dibutuhkan termasuk dalam kegiatan program ASI eksklusif yaitu berasal dari Anggaran Pendapatan dan Belanja Negara. Dana untuk mendukung pelaksanaan kebijakan ASI eksklusif di tempat kerja perlu pengalokasian yang lebih sesuai, karena pengembangan kebijakan ASI eksklusif di tempat kerja harus diiringi dengan berbagai program inovasi untuk membuahkan hasil yang lebih signifikan. Implementasi suatu kebijakan harus didukung dengan adanya anggaran yang memadai untuk menjamin terlaksananya penerapan ASI eksklusif di tempat kerja, sebab tanpa anggaran yang cukup, kebijakan tidak akan berjalan dengan efektif. Agar dana ini efektif dan terarah dalam penggunaannya perlu adanya program kerja yang jelas dan berpihak kepada pekerja/buruh. Untuk menjamin implementasi dapat berjalan dengan lancar kepada kelompok sasaran perlu didahului dengan penyampaian informasi kepada kelompok sasaran. Tujuan pemberian informasi agar kelompok sasaran memahami kebijakan yang akan diimplementasikan sehingga mereka tidak hanya dapat menerima berbagai program yang diinisiasikan oleh pemerintah akan tetapi berpartisipasi aktif dalam upaya untuk mewujudkan tujuan-tujuan kebijakan. Sarana merupakan salah satu faktor yang berpengaruh dalam implementasi kebijakan. Sarana dan prasarana harus dimiliki oleh pelaksana kebijakan agar kegiatan-kegiatan yang dilaksanakan dapat berjalan dengan efektif dan efisien.

Sarana dan prasarana pemberian ASI eksklusif di tempat kerja disediakan oleh pengurus tempat kerja. Penyediaan ruang menyusui terngantung dari UPD masing-masing instansi tempat kerja. Sarana dan prasarana yang tersedia untuk pelaksanaan ASI Eksklusif berupa poster, leaflet dan buku saku yang berasal dari promosi kesehatan dinas kesehatan yang akan diberikan kepada ibu hamil dan menyusui yang datang ke wilayah kerja puskesmas. Walaupun sudah ada sarana dari promosi kesehatan, namun kenyataannya masih ada ibu-ibu yang tidak mengerti manfaat ASI. Henderawaty et al (2014) menjelaskan bahwa dana yang cukup dan sesuai untuk melakukan sosialisasi, pengadanaan tenaga yang bertanggungjawab terhadap jalannya kebijakan, sarana prasarana untuk sosialisasi dan penyebaran informasi kebijakan agar berjalan optimal. ${ }^{16}$

Perencanaan adalah suatu proses kerja yang terus menerus dilakukan berfungsi untuk melakukan manajemen kinerja organisasi di masa depan, mengambil keputusan yang bersifat pokok dan penting, memutuskan tugas dan penggunaan sumber daya yang diperlukan dalam organisasi untuk mencapai tujuan. Pengorganisasi dalam pelaksanaan tentang ASI eksklusif melibatkan semua instansi tempat kerja pemerintah dan swasta dibawah koordinir Dinkes, Depnaker dan PPPA untuk menghimbau. Pelaksanaan untuk masing-masing tempat kerja merupakan tanggung jawab pimpinan tempat kerja, sedangkan pengawasan dilakukan oleh PPPA selaku 
anggota Kegiatan Kabupaten Layak Anak, pengorganisasian dalam pelaksanaan ASI eksklusif di tempat kerja hanya melibatkan pimpinan-pimpinan instansi tempat kerja. Ibu bekerja yang menyusui tidak mengetahui mengenai pengorganisasian dalam pelaksanaan ASI eksklusif di tempat kerja.

Kegiatan implementasi kebijakan, struktur organisasi merupakan wadah atau wahana interaksi dimana para petugas, aparat birokrasi, atau pejabat berwenang mengelola implementasi kebijakan dengan berbagai kegiatannya. Proses terbentuknya organisasi merupakan serangkaian logika penyederhanaan kerja yang terdiri dari: adanya kebutuhan untuk melakukan pembagian kerja diantaranya anggotanya karena pekerjaan untuk mencapai misi organisasi tidak dapat dilakukan sendiri. Sebagai konsekuensi dari berbagai departemen, unit kerja, dan individu-individu yang memiliki tugas berbeda-beda dan individu-individu yang diberi tugas tersebut menjalankan kewajibannya dengan baik sesuai dengan panduan yang telah ditetapkan.

Pelaksanaan program ASI eksklusif di tempat kerja sesuai dengan wawancara dengan kepala seksi gizi dinas kesehatan Kabupaten OKU menyatakan bahwa akan membuat kelompok pendukung ASI. pihak pemberdayaan perempuan OKU akan melaksanakan kegiatan Kabupaten Layak Anak, pihak dinas tenaga kerja akan menghimbau atasan kerja untuk menyediakan ruang menyusui dan membuat peraturan waktu kerja untuk ibu menyusui yang bekerja, sedangkan puskesmas akan memberitahu tentang ASI kepada ibu-ibu hamil dan menyusui yang datang ke wilayah kerja puskesmas.

Permasalahan yang terjadi di pelaksanaan adalah tidak ada sanksi tegas kepada tempat kerja jika tidak melaksanakan kewajiban tersebut dan Petugas lapangan yang kurang mengetahui mengenai manajemen laktasi. Solusi yang dapat digunakan untuk mengatasi permasalahan ini adalah membuat peraturan daerah yang mengatur mengenai ASI Ekslusif di tempat kerja, melakukan penyuluhan dan pelatihan mengenai manajemen laktasi kepada petugas gizi di lapangan. Pengawasan adalah suatu proses untuk menjamin bahwa pelaksanaan kegiatan/ pekerjaaan sesuai dengan rencana, pendoman, ketentuan kebijakan, tujuan dan sasaran yang sudah ditentukan tercapai. Pemantauan dilakukan untuk mengetahui perkembangan maupun permasalahan serta menemukan pemecahan dalam pengelolaan dan pelaksanaan ASI eksklusif di tempat kerja sesuai dengan rencana yang telah ditetapkan.

Indikator ASI eksklusif di tempat kerja menurut Kemenkes adalah sebagai berikut Indikator Input; adanya perencanaan mengenai ruang $\mathrm{ASI}$, adanya sarana dan prasarana ruang ASI sesuai dengan standar minimal dan sesuai kebutuhan, adanya tenaga kesehatan dan/atau tenaga non kesehatan sebagai tenaga terlatih Pemberian ASI, adannya pendanaan yang dilarang bersumber dari produsen atau distributor susu formula bayi. Indikator proses, pengurus tempat kerja mendukung perencanaan, pembinaan dan pengawasan dilakukan melalui advokasi, sosialisasi dan bimbingan teknis peningkatan pemberian ASI eksklusif, dilaksanakan monitoring dan evaluasi. ${ }^{17}$

\section{SIMPULAN}

Sosialisasi kepada pimpinan tempat kerja mengenai kebijakan sudah dilakukan melalui himbauan di sela-sela kegiatan lain, namun secara khusus membahas pemberian ASI eksklusif di tempat kerja belum terlaksana dikarenakan belum adanya dana untuk kegiatan tersebut. Tenaga terlatih, dana serta sarana dan prasarana pemberian ASI eksklusif di tempat kerja belum ada dikarenakan anggaran biaya terngantung pengurus tempat kerja. Perencanaan sedang mulai dilakukan berupa pembentukan kelompok pendukung ASI, penyuluhan pada ibu-ibu bekerja yang datang ke wilayah kerja fasilitas pelayanan kesehatan, dan pendataan tempat kerja yang telah memiliki fasilitas laktasi. Pembagian tugas untuk Pemberian ASI di tempat kerja belum ada sehingga pelaksanaan belum optimal untuk monitoring kebijakan tersebut. Pemberian ASI eksklusif di tempat kerja yaitu terbentuknya ruang menyusui sesuai standar minimal dan sesuai, pengaturan jam kerja, dan pembuatan peraturan internal masih belum terlaksana di Kabupaten OKU. 


\section{SARAN}

Dinas kesehatan diharapkan untuk menyelenggarakan pelatihan manajemen laktasi dan konseling menyusui untuk menyediakan staf yang terlatih di fasilitas pelayanan kesehatan dan tempat kerja sehingga memiliki keahlian dalam hal pemberian ASI. Dinas tenaga kerja dan transmigrasi diharapkan agar memberikan sosialisasi kebijakan secara khusus kepada para pimpinan tempat kerja mengenai kebijakan pemberian ASI eksklusif di tempat kerja.

\section{UCAPAN TERIMAKASIH}

Terimakasih kepada responden, Kasie gizi dinas kesehatan, Kabid hubungan industrial dinas tenaga kerja dan transmigrasi, Kabid pemberdayaan perempuan dinas perlindungan dan pemberdayaan perempuan dan anak di Kabupaten Ogan Komering Ulu.

\section{DAFTAR PUSTAKA}

1. World Health Organization (WHO). Infant and young child feeding. 2018 (diakses 14 agustus 2018. Tersedia dari: http://www.who.int/en/newsroom/ fact-sheets/detail/infant-and-young-childfeeding.

2. Kementerian Kesehatan RI (Kemenkes RI). Buku saku pemantauan status gizi (PSG) tahun 2017. Jakarta: Kemenkes RI; 2018

3. Taradisa NU, Sormin T, Musiana. Hubungan pengetahuan dan pekerjaan ibu dengan pemberian ASI eksklusif di wilayah kota Bandar Lampung. Jurnal Keperawatan. 2016;13(2):190-6.

4. Badan Pusat Statistik (BPS) Kabupaten Ogan Komering Ulu. Kabupaten Ogan Komering Ulu dalam angka 2018. BPS Kabupaten Ogan Komering Ulu; 2018.

5. Undang-Undang Republik Indonesia no 33 tahun 2012. pemberian air susu ibu eksklusif. Jakarta: Lembar Negara Republik Indonesia Tahun 2012 Nomor $5291 ; 2012$.

6. Olang B, Hedarzadeh A, Strandvik B, Yngve A. Reasons given by mothers for discontinuing breastfeeding in Iran. International Breastfeeding Journal. 2012 (diunduh 5 Mei 2019). Tersedia dari: https://internationalbreastfeedingjournal.biomedcen tral. com/articles/ 10.1186/ 1746-4358-7-7.
7. Inoue $M$, Binns CW, Outsuka $K$, Jimba $M$, Matsubara M. Infant feeding practice and breastfeeding duration in Japan: A review. International breastfeeding Journal. 2012 (diunduh 20 Mei 2019). Tersedia dari: https://internationalbreastfeedingjournal. biomedcentral.com/articles/10.1186/ 1746-4358-7-15.

8. Australian Breastfeeding Association. The WHO code. 2018 (diakses 20 Mei 2019).Tersedia dari : https://www.breastfeeding.asn.au/who-code

9. Bono D, Emilia, Pronzato, Daniela C. Does breastfeeding support at work help mothers and employers at the same time? Australian Breastfeeding Association. 2012 (diunduh 20 Mei 2019). Tersedia dari: https://www.econstor.eu/ bitstream/10419/65922/1/689516282.pdf

10. Dun-Dery EJ, Laar AK. Exclusive breastfeeding among city-dwelling professional working mothers in Ghana. International Breastfeeding Journal. 2016 (diunduh 19 Mei 2019). Tersedia dari: https://internationalbreastfeedingjournal.biomedcen tral.com/articles/10.1186/s13006-016-0083-8

11. Amin RM, Said ZM, Sutan R, Shah SA, Darus A, Shamsuddin K. Work related determinants of breastfeeding discontinuation among employed mothers in Malaysia. International breastfeeding Journal. 2011 (diunduh 15 november 2018). Tersedia dari: http://www.international breastfeeding journal.com/content/6/1/4

12. Monica FB. Buku pintar ASI dan menyusui. Jakarta: Noura Books (Mizan Group); 2018.

13. Osibogun OO, Olufunlayo TF, Oyibo SO. Knowledge, attitude and support for exclusive breastfeeding among bankers in Mainland Local Goverment in Lagos State, Nigeria. International. Breastfeeding Journal. 2018 (diunduh 22 September 2018). Tersedia dari: https://www .ncbi.nlm.nih.gov/pmc/articles/PMC6106889/pdf/13 0062018 Article 182.pdf

14. Weber D, Janson A, Nolan M, Wen LM, Rissel C. Female employees' perceptions of organisational support for breastfeeding at work: findings from an Australian health service workplace. International Breastfeeding Journal.2011 (diunduh 15 mei 2019). Tersedia dari: https://international 
breastfeedingjournal.biomedcentral.com/articles/10 $.1186 / 1746-4358-6-19$

15. Paramashanti BA, Anwar C, Kartika M. Implementasi kebijakan bupati Bantul nomor 82 tahun 2012 tentang pemberian ASI eksklusif di Kabupaten Bantul. Jurnal Riset Daerah. 2017;16 (3): 2815-34.

16. Henderawaty R, Kartasurya MI, Suparwati A.
Analisis implementasi kebijakan pemberian air susu eksklusif BGI lbu bekerja di provinsi Kalimantan Selatan. Jurnal Manajemen Kesehatan Indonesia. 2014;2(1):36-3.

17. Undang-Undang Republik Indonesia No 15 tahun 2013. Tata cara penyediaan fasilitas khusus menyusui dan/ atau memerah air susu ibu. Jakarta: Lembaran Negara RI tahun 2012, No. 441; 2012. 